\title{
O envelhe(s)er na voz de quem o vivencia: narrativas de participantes de um Programa UATI no semiárido baiano
}

\section{Aging in the voice of those who experience it: narratives of the participants of a UATI program in the semiarid region of Bahia}

\author{
Ana Vitória Lima Ferreira ${ }^{1}$; Amanda Leite Novaes ${ }^{1}$; José Fernando Andrade Costa ${ }^{1}$; \\ Suzana Alves Nogueira Souza ${ }^{1}$; Hernandes Machado de Jesus ${ }^{1}$
}

\begin{abstract}
RESUMO
A construção identitária do "ser idoso" passou e ainda passa por diversas mudanças desde o estabelecimento da velhice enquanto uma categoria etária, sendo que, muitas vezes, o discurso sobre a velhice se sobrepõe ao discurso dos próprios velhos sobre sua experiência de vida. Diante disso, o presente trabalho tem por objetivo analisar as narrativas das idosas participantes de uma oficina do programa extensionista Universidade Aberta à Terceira Idade da Universidade Estadual de Feira de Santana sobre o que, para elas, é ser idosa. Quanto ao método, este trabalho se configura como uma pesquisa qualitativa, cujos instrumentos de coleta dos dados foram a observação participante e a entrevista baseada em roteiro semiestruturado com duas idosas. Após a coleta, os dados foram analisados à luz da análise de conteúdo de Bardin. As narrativas das participantes, embora apontem as mudanças corporais, como as rugas e cabelos brancos como uma realidade, muitas vezes, difícil de enfrentar, ressaltam aspectos como o aprendizado e o desejo de se manterem ativas, demonstrando em suas falas estar encarando o processo de envelhecimento com leveza e naturalidade.
\end{abstract}

Palavras-chave: Identidade; Envelhecimento; Universidade Aberta à Terceira Idade.

\begin{abstract}
The identity construction of "being elderly" has undergone and still undergoes several changes since the establishment of old age as an age category, and the discourse on old age often overlaps with the discourse of the elderly themselves about their life experience. Therefore, the present work aims to analyze the narratives of the elderly women participating in a workshop of the extension program Open University for the Elderly at State University of Feira de Santana about what it means to be elderly, for them. As for the method, this work is configured as qualitative research, whose data collection instruments were participant observation and an interview based on a semi-structured script with two elderly women. After collection, data were analyzed in light of Bardin's content analysis. The participants' narratives, although they point to bodily changes, such as wrinkles and gray hair, as a reality that is often difficult to face, emphasize aspects such as learning and the desire to remain active, demonstrating in their speeches that they are facing the aging process with ease and naturalness.
\end{abstract}

Key words: Identity; Aging; Open University for the Elderly.

\footnotetext{
1 Universidade Estadual de Feira de Santana

* anavitoriapsicologia@gmail.com
} 


\section{INTRODUÇÃO}

O presente artigo aborda o problema do estudo sobre a velhice a partir da experiência de vida dos próprios sujeitos do envelhecimento. A velhice ou o "ser idoso" é um processo biopsicossocial que envolve múltiplos aspectos da vida: passagem do tempo, transformações corporais, produtivas, relacionais, de cidadania etc. Muitas vezes, entende-se por idosa a pessoa que possui 60 anos de idade ou mais, como se a velhice fosse uma aquisição de data de aniversário. Isso decorre do advento da categoria "terceira idade" que vai muito além da idade cronológica e apresenta desafios para a sociedade cuidar de seus membros mais velhos. Esse é o caso, como veremos, da Universidade Aberta à Terceira Idade.

Mas o discurso sobre a velhice não pode se sobrepor ao discurso dos próprios idosos sobre seu processo de envelhecimento, sob pena de se cair em um reducionismo ou reificação do processo de tornar-se velho. Neste sentido, tendo em vista essa problemática e o interesse em contribuir para o campo de estudos e práticas sobre o envelhecimento, nesta pesquisa abordaremos o problema desde a perspectiva da construção identitária do "ser idoso", recorrendo à voz das participantes de uma oficina de um Programa extensionista Universidade Aberta à Terceira Idade.

Convém apresentar, num primeiro momento, uma concepção teórica de base psicossocial sobre o desenvolvimento da identidade como metamorfose; em seguida, ponderar o advento da categoria "terceira idade" e suas implicações para a compreensão da velhice.

\section{Identidade-metamorfose e a velhice}

Para Antônio Ciampa (2005) identidade é metamorfose e se constrói em um contínuo ao longo da vida. Uma trajetória de vida é repleta de mudanças, sem que deixemos de sermos nós mesmos. Essa característica da identidade como metamorfose - em oposição a definições estáticas - apoia-se no fato de que em todos os contextos em que estamos inseridos desempenhamos os mais diferentes papéis sociais: somos filhos, irmãos, estudantes, amigos... somos personagens e protagonistas de nossa própria vida. Mas, como somos seres sociais, nossas distintas personagens se constroem a partir das relações sociais que vamos estabelecendo com os outros e com o mundo em que vivemos, tornando assim as pessoas com quem interagimos coautoras da nossa história (CIAMPA, 2005).

A interação social desempenha um papel fundamental não apenas para a construção, mas também para a legitimação desses personagens (CIAMPA, 2005). Por exemplo, para desempenhar o papel de profissional, seja qual for a área, é preciso que haja reconhecimento por parte de um grupo mais experiente de que se está apto para tal função. Isso significa que a identidade individual é sempre social, no sentido de que é construída historicamente, por meio da 
teia de relações sociais que configuram nossa forma de vida. Compreendido dessa forma ${ }^{2}$, o conceito psicossocial de identidade constitui uma ferramenta útil para análise abrangente de processos de desenvolvimento humano em diferentes etapas, como, por exemplo, o envelhecimento.

Como observou Marilena Chauí (2012), ao comentar o trabalho seminal de Ecléa Bosi Memória e Sociedade, os velhos são os guardiões do passado e, no entanto, não possuem armas: nós é que temos que lutar por eles. Isso não significa que a velhice seja causa de impotência, pelo contrário, é a sociedade capitalista que não tolera a velhice. Desse modo, na velhice a pessoa encontra-se vulnerável ao processo de reconhecimento perverso descrito por Aluísio Lima (2010), segundo o qual o reconhecimento social é conferido de forma distorcida, de modo que a garantia de direitos e o acesso a serviços públicos ficam dependentes de um discurso reificado sobre o que supostamente deve ser um idoso. Nesse processo, o discurso sobre o idoso se sobrepõe ao discurso do idoso.

Como podemos observar na literatura, o envelhecimento ainda hoje é vinculado a discursos pejorativos e estigmatizados, que apontam as perdas físicas, o adoecimento e as limitações como uma realidade universal, e isso impacta tanto na forma como as pessoas encaram essa fase da vida, que a maioria delas teme envelhecer (DEBERT, 1999; SILVA, 2008; BARROSO, 2021).

Todavia, de acordo com Debert (1999) essa visão negativa da velhice se constituiu como um elemento fundamental para a legitimação de direitos sociais como, por exemplo, a universalização das aposentadorias. Então, embora este tenha sido um passo importante para o estabelecimento da velhice enquanto categoria etária, foi também responsável pela associação inequívoca entre velhice e invalidez (SILVA, 2008).

A estabilização das categorias etárias passou a definir funções, hábitos, características de conduta, ideais de satisfação, comportamentos e a experiência de "habitar" qualquer das etapas do curso da vida (SILVA, 2008; MOTTA, 2019), favorecendo a criação do que Silva (2008) denominou de identidades etárias. Sendo a identidade uma construção de autoria coletiva, na qual, os personagens com quem nos relacionamos desempenham papel fundamental na construção da história (CIAMPA, 2005), essas regras de conduta, passam a influenciar tanto a maneira como cada fase é vista socialmente, quanto a própria vivência das pessoas (SILVA, 2008).

A socióloga Alda Britto da Motta (2019, p. 362), inspirada em Simone de Beauvoir, afirma que "a velhice chega primeiro pelos olhos dos outros", um olhar carregado de julgamentos,

\footnotetext{
${ }^{2}$ Existem diversas correntes teóricas sobre o fenômeno de individuação humana apoiadas em conceitos como personalidade, Ego, self, pessoa, sujeito etc. Mesmo entre os estudos sobre identidade há diferentes compreensões do processo de formação do eu. Por isso adotamos aqui as contribuições do que podemos chamar de "Escola da teoria da Identidade-Metamorfose", desenvolvida sob liderança de Antônio da Costa Ciampa no Núcleo de Estudos e Pesquisas em Identidade-Metamorfose (NEPIM-PUCSP).
} 
avaliações, expectativas e preconceitos que tornam o envelhecer uma "condição difícil de ser assumida". Isso faz pensar como surgiu a noção de "terceira idade" como sinônimo de velhice.

\title{
O advento da "terceira idade"
}

Embora haja poucos estudos históricos sobre o advento da categoria "terceira idade" (SILVA, 2008), Debert (1999; 2011) afirma que essa expressão surge na década de 1970 com a criação da primeira Universidade para a Terceira Idade, na França. Silva (2008) aponta como possíveis fatores para esse surgimento a reorganização e generalização dos sistemas de aposentadoria, os interesses da cultura do consumo e a substituição dos termos de tratamento da velhice. Nesse sentido, a referida autora traz que o advento dessa nova categoria gerou uma profunda mudança nos valores atribuídos a essa fase da vida, que

\begin{abstract}
antes entendida como decadência física e invalidez, momento de descanso e quietude no qual imperavam a solidão e o isolamento afetivo, passa a significar o momento do lazer, propício à realização pessoal que ficou incompleta na juventude, à criação de novos hábitos, hobbies e habilidades e ao cultivo de laços afetivos e amorosos alternativos à família (SILVA, 2008, p. 161).
\end{abstract}

Essas novas imagens atreladas ao envelhecer são expressão de um contexto marcado por mudanças culturais que redefinem a intimidade e a construção das identidades (DEBERT, 1999). Ou seja, a forma como o sujeito vivencia esta etapa da vida, assim como qualquer outra, e sua construção identitária, vão depender do que é socialmente estabelecido para aquele grupo, uma vez que

o conhecimento de si é dado pelo reconhecimento recíproco dos indivíduos identificados através de um determinado grupo social que existe objetivamente, com sua história, suas tradições, suas normas, seus interesses etc (CIAMPA, 1989, p. 64).

Dessa forma, a construção identitária do "ser velho" passou, e ainda passa, por profundas transformações, desde o seu estabelecimento enquanto categoria etária - quando estava atrelada à decadência física, incapacidade produtiva e isolamento afetivo - até os dias de hoje, em que prevalece um discurso voltado à busca por satisfação pessoal, cultivo de laços afetivos e criação de novos hábitos (DEBERT, 1999), o que a Organização Mundial de Saúde (OMS) chama de envelhecimento ativo (OMS, 2005).

De acordo com a OMS (2005, p. 13), o "envelhecimento ativo é o processo de otimização das oportunidades de saúde, participação e segurança, com o objetivo de melhorar a qualidade de vida à medida que as pessoas ficam mais velhas".

Seguindo esses mesmos princípios, Vieira e Costa (2019, p. 184) apontam que o envelhecimento ativo "atende aos princípios da dignidade, autonomia, independência, 
participação social, assistência e autorrealização da pessoa idosa", envolvendo tanto a promoção de saúde física e mental, quanto os fatores sociais (OMS, 2005). Foi então que, visando promover um envelhecimento com qualidade de vida, surgem na década de 1960, os primeiros programas para idosos, no entanto, somente na década de 1990 que eles se propagam pelas cidades brasileiras (DEBERT, 1999).

A primeira Universidade da Terceira Idade instaurou-se em 1990, na Universidade Católica de Campinas, visando proporcionar a esse público um ambiente de "aprendizagem e culturalmente estimulante, de diálogo entre seus pares, de exercício da cidadania, para ocupação do tempo livre e de estabelecimento de redes sociais" (CACHIONI, 2012, p.4).

Existem no Brasil mais de 200 programas dessa natureza, que, em sua maioria, caracterizam-se como projetos e programas de extensão em instituições de ensino superior (CACHIONI, 2012). Este é o caso da Universidade Aberta à Terceira Idade (UATI) da Universidade Estadual de Feira de Santana (UEFS), que, desde 1992, vem mudando a rotina de centenas de idosos, tendo como objetivo

\begin{abstract}
"estimular a promoção da saúde, a socialização dos saberes, a prática de esportes, o exercício consciente da cidadania, as relações sociais, o lazer, a arte, a cultura, a inclusão digital, a reinserção no setor produtivo, a reintegração sócio-comunitária, o fortalecimento dos vínculos familiares, o equilíbrio psicossomático, a preparação para a Terceira Idade e a educação permanente" (UEFS, [s.d]).
\end{abstract}

Uma das oficinas ofertadas pela UATI é a de Práticas Integrativas, implementada através do plano de trabalho intitulado "Práticas Integrativas e Complementares (PICS) na ressignificação do envelhecer", o qual foi pensado tendo em vista que, mesmo após tantas mudanças e debates públicos sobre o envelhecimento, a percepção comum sobre velhice ainda é permeada por estereótipos negativos e preconceitos (DEBERT, 1999; SILVA, 2008). Então, diante dessa necessidade de se propagar a existência de outras possibilidades para um envelhecer saudável e prazeroso e promover ações que viabilizassem isso, é que surgiu a proposta da oficina.

O desenvolvimento deste projeto extensionista, aflorou o interesse por investigar as contribuições da oficina para a construção identitária de suas participantes e assim nasceu o Trabalho de Conclusão de Curso intitulado "Contribuições da Oficina de Práticas Integrativas da UATI/UEFS na (re)construção identitária: narrativas das idosas participantes", cujo recorte consiste no foco deste trabalho.

Assim, o presente artigo tem como objetivo analisar as narrativas de duas idosas participantes da Oficina de Práticas Integrativas do programa extensionista UATI da UEFS sobre o que é ser idosa.

\title{
MÉTODO
}


Trata-se de um estudo de abordagem qualitativa cujo delineamento se deu enquanto uma pesquisa participante, realizada junto ao programa extensionista Universidade Aberta à Terceira Idade da Universidade Estadual de Feira de Santana no qual, foi desenvolvido um trabalho como bolsista através da execução do plano extensionista intitulado "Práticas Integrativas e Complementares na ressignificação do envelhecer".

Os critérios de inclusão na pesquisa foram a idade (acima de 60 anos), ser integrante da oficina há, pelo menos, quatro meses e participar através de comentários e feedbacks das quatro oficinas temáticas (ou do maior número delas) - cujos temas foram: $1 \mathrm{O}$ que é envelhecer; 2 corpo e saúde; 3 amizades e 4 família - promovidas por meio de postagens de vídeos no grupo do Whatsapp.

Diante disso, foram selecionadas duas participantes, Rosa, de 77 anos, e Lírio, de 65. Cabe salientar, que estes são nomes fictícios utilizados para garantir o anonimato das participantes.

Quanto à coleta de dados, os instrumentos foram selecionados a partir da teoria de Brandão (1999), à vista disso, foram utilizadas a observação participante e as entrevistas individuais (uma) baseadas em roteiros semi-estruturados.

Ademais, os dados foram analisados à luz da Análise de Conteúdo de Bardin (1977), cujos procedimentos para a realização abrangem: a pré-análise, etapa inicial em que o material é selecionado e preparado para as etapas seguinte; a exploração do material, que consiste no processo de codificação e categorização do material; e o tratamento dos resultados etapa em que os dados são interpretados à luz do referencial teórico escolhido (BARDIN, 1977).

Por fim, é importante ressaltar, que a pesquisa foi submetida e aprovada pelo Comitê de Ética em Pesquisa com seres humanos da Universidade Estadual de Feira de Santana, sob CAAE 26298419.8.0000.0053 e número do parecer é 3.853.501.

\section{RESULTADOS E DISCUSSÃO}

O corpus deste trabalho foi construído a partir das entrevistas com duas idosas participantes da oficina de Práticas Integrativas que atenderam aos critérios de inclusão na pesquisa. Todavia, antes de apresentar os resultados alcançados, se faz necessário contextualizar 
a presente pesquisa, pois a mesma foi atravessada pelo contexto de isolamento ocasionado pela pandemia de Covid-1933, o que impactou diretamente na realização deste estudo.

Essa pandemia que surpreendeu o mundo, mudou a vida de todos, sem exceção. Alterou a rotina, os cuidados com a saúde, a higiene, a forma de fazer compras, de sair de casa, de voltar para casa, de se cumprimentar, de tocar o outro, de se relacionar. Com a oficina, então, não poderia ser diferente.

Diante desse contexto, as oficinas, que aconteciam semanalmente de maneira presencial, foram suspensas e, após muitas adaptações, retornaram em contexto totalmente virtual. Com isso, os bate-papos acalourados deram lugar às mensagens e áudios no grupo do whatsapp e as vivências que arrancavam sorrisos e abraços foram substituídas por vídeos que, apesar de todo esforço em transmitir carinho, alegria e esperança, nunca poderiam se comparar à riqueza do que era vivido e sentido no presencial. Mas, foi assim que a oficina se reinventou.

Com isso, a coleta de dados, antes idealizada como uma entrevista presencial de caráter mais informal, com possibilidade de observação das reações e do contato, foi realizada através de vídeo chamada e o distanciamento, a timidez e os ruídos na comunicação interferiram bastante no processo.

Dessa forma, o que será aqui apresentado é o fruto de um trabalho atravessado por esse contexto que afetou pesquisadores e participantes, mas que, mesmo assim, seguiu todo o rigor de uma pesquisa científica e tem informações relevantes a serem compartilhadas.

A análise dos dados obtidos neste estudo evidencia, a partir do conteúdo das respostas das idosas participantes, a presença de elementos que foram agrupados em 4 (quatro) categorias de análise, que serão detalhadas a seguir.

A primeira delas foi intitulada "História de vida", a qual elenca os momentos que, para as entrevistadas, foram marcantes, com foco especial nos momentos considerados mais difíceis e os mais prazerosos. A segunda foi a "UATI" que tratou sobre as mudanças que o ingresso no programa provocou na rotina das participantes, sem esquecer o contexto pandêmico. A terceira categoria foi a "Oficina de PICS" que versou sobre o papel da oficina, os momentos marcantes, os aprendizados e mudanças geradas a partir dela. Por fim, a categoria "Envelhecimento", que é o foco do presente artigo, abordou a visão das duas entrevistadas sobre seu próprio processo de envelhecimento e as mudanças decorrentes dele.

A partir da narrativa das participantes, as unidades de sentido mais marcantes sobre a visão que elas têm de seu processo de envelhecimento foram o desejo de permanecerem ativas e

\footnotetext{
${ }^{3}$ Covid-19 foi o nome dado à síndrome do coronavírus, que tem atingido pessoas em diferentes graus de complexidade, sendo sua manifestação mais grave uma insuficiência respiratória aguda que demanda cuidados hospitalares intensivos (FARO et al, 2020).
} 
realizarem suas atividades, a aceitação da terceira idade como uma realidade e uma visão positiva do processo, como mostra o quadro abaixo.

Quadro 01: Envelhecimento

\begin{tabular}{|c|c|c|}
\hline CATEGORIA & SUBCATEGORIA & UNIDADES DE SENTIDO \\
\hline \multirow{5}{*}{ Envelhecimento } & \multirow{2}{*}{ Visão do processo } & Aceitação e visão positiva da terceira idade; \\
\hline & & Desejo de continuar realizando suas atividades; \\
\hline & \multirow{3}{*}{$\begin{array}{c}\text { Mudanças com a } \\
\text { idade }\end{array}$} & Aprendizado; \\
\hline & & Rugas e cabelos brancos; \\
\hline & & Desejo de permanecer ativa; \\
\hline
\end{tabular}

Fonte: FERREIRA, 2021

Contudo, antes de tratar sobre a visão das entrevistadas sobre seu processo de envelhecimento, é importante ressaltar algo que, apesar de parecer óbvio, não é levado em consideração por grande parte da sociedade: a velhice é plural (DEBERT, 1999; 2019; MOTTA, 2019). Há pessoas que envelhecem sem perder o vigor, outras ficam mais debilitadas, umas aceitam esse processo com naturalidade, enquanto outras podem encarar as mudanças como um fardo, isso sem pesar a influência de aspectos como gênero, raça, sexualidade e condições socioeconômicas (DEBERT, 1999; MOTTA, 2019).

Nessa perspectiva, Santos e Bastos (2019, p. 243) realizaram uma pesquisa com professoras aposentadas, às quais, questionaram sobre os significados de envelhecer e as respostas variaram desde "é muito bom, viver é ótimo", até "envelhecer é a pior doença que existe". Isso demonstra o quanto esse processo é singular e precisa ser encarado como tal.

Porém, no que tange à Lírio e Rosa, participantes deste estudo, essas demonstraram estar encarando o processo com naturalidade, como atestam as falas a seguir, em que ambas foram questionadas sobre como se sentem nessa fase da vida

Graças a Deus cheguei até essa fase, né? [...] me sinto feliz, tendo saúde (risos). (Rosa)

É isso que eu tô te dizendo, tem que aceitar porque, tem um dizer antigo que o povo diz,[...] que quem não quer envelhecer morre novo, então a gente não quer morrer, quer? A gente quer viver, não é isso? (Lírio) 
Porém, essa aparente aceitação do processo que ambas demonstraram não significa que as mudanças advindas com a velhice, em especial, as que afetam o corpo não sejam impactantes. A exemplo disso, Lírio, ao ser questionada se algo mudou com a idade, afirmou

[...] É, mudar muda né? Assim, muda... vem os cabelo branco, tem as ruga né? mas a gente tem que aceitar. (Lírio)

Nessa perspectiva, estudos apontam o corpo como alvo de insatisfação na velhice, (NASCIMENTO, 2012; BAPTISTA, 2014; DEBERT, 2019), como atesta a pesquisa realizada por Baptista (2014) em uma Universidade Aberta à Terceira Idade do estado de Goiás, a qual apontou que, entre os 18 idosos investigados, 61,11\% apresentavam o corpo pelas suas características negativas, ressaltando as dores, a fragilidade e o adoecimento.

Essa insatisfação pode estar relacionada aos padrões de beleza veiculados nas propagandas, novelas, programas de TV e revistas, que, de acordo com Debert (2019, p. 30), associam boa aparência a sensação de bem estar e propagam que as "imperfeições do corpo não são naturais nem imutáveis". Partindo desse discurso, as marcas do envelhecimento, como os cabelos brancos, as rugas ou a flacidez da pele, transformam-se em indícios de descuido e desleixo (DEBERT, 2019).

É importante salientar, que esses padrões servem a toda uma indústria do rejuvenescimento, com suas vitaminas, cosméticos e procedimentos estéticos que ditam o que é belo e aceitável não só para as idades mais avançadas, mas para qualquer das etapas da vida (DEBERT, 2019). No entanto, é preciso destacar que as cobranças, julgamentos e acusações recaem muito mais sobre as mulheres do que sobre os homens (NASCIMENTO, 2012), pois, como afirmam Santos e Bastos (2019, p. 236), em nossa sociedade "o homem velho e calvo é durão e viril, a mulher idosa é a imagem da decadência".

Ademais, ao direcionar a mesma questão a Rosa, sobre as mudanças advindas com a idade, essa abordou um aspecto totalmente diferente, e falou a respeito do aprendizado

Passou por muita coisa né? Cada momento é uma fase, né? Na vida da gente, né? A gente aprende (inaudível). (Rosa)

Tanto o aprendizado quanto a sabedoria e a experiência de vida, são aspectos comumente ressaltados como positivos quando o assunto são os ganhos com a velhice (MARTINS; CAMARGO; BIASUS, 2008; MENESES et al, 2013; DE PAULA, 2016).

Em uma pesquisa sobre as representações sociais de "pessoa velha" (SANTOS; TURA; ARRUDA, 2013), a qual contou com 70 participantes com idades entre 60 e 83 anos, foram realizados testes de evocação livre, em que, os termos "experiência" e "sabedoria" corresponderam a 28 e 12 evocações, respectivamente. 
Semelhantemente, o estudo de Martins, Camargo e Biasus (2008) com 71 pessoas de diferentes faixas etárias, sendo 23 adolescentes, 21 adultos e 27 idosos, apresentou que os não idosos vinculam esta etapa da vida à experiência e sabedoria.

Por fim, outro aspecto levantado pelas participantes sobre a fase da vida em que se encontram, foi o desejo que ambas têm de se manterem ativas

Quero sair um pouco, me divertir, pra me distrair, participar de alguma coisa, de algum exercício...(Rosa)

Então assim, não é porque eu tô com essa idade que eu vou ficar, sabe? Ficar num canto, então eu começo entrar no meio da conversa. Eu começo dar risada, começo brincar, e vamo levando a vida né? (Lírio)

Esse desejo de manter-se engajado em atividades na velhice é apontado por Santos e Bastos (2019) como algo fundamental, à medida em que ameniza sentimentos de solidão e isolamento. As autoras afirmam ainda, que "a prática religiosa, a participação em grupos de apoio, o engajamento em atividades filantrópicas fornece bem estar emocional na velhice" (SANTOS; BASTOS, 2019, p.247).

\section{CONSIDERAÇÕES FINAIS}

Falar sobre identidade é falar de mudança, pois identidade é metamorfose e se (re)constrói ao longo da vida a partir das relações sociais em que cada indivíduo se engendra. Nesse sentido, a interação social exerce papel fundamental em nossas vidas, não apenas para a construção, mas também para o reconhecimento e legitimação dos personagens que representamos. Cabe salientar, que esse reconhecimento, ou a ausência dele, pode impactar a própria forma como o indivíduo se vê.

Nessa perspectiva, a velhice ao ser estabelecida enquanto uma categoria foi, inicialmente, atrelada a estereótipos negativos que a associavam, principalmente, às perdas físicas e limitações e, embora essa associação tenha sido fundamental para legitimação de direitos sociais e criação de políticas públicas voltadas à proteção da pessoa idosa, e que o advento da terceira idade tenha trazido consigo novas possibilidades de vivenciar essa fase da vida, parte desse discurso pejorativo ainda perdura até os dias de hoje.

Porém, no que concerne às participantes desta pesquisa, essas demonstraram encarar o processo de envelhecimento com naturalidade, e apesar de apontarem as mudanças corporais como uma realidade, muitas vezes, difícil de enfrentar, ressaltam aspectos positivos, tais como o aprendizado adquirido com a idade e o desejo de permanecerem ativas, demonstrando encarar essa fase da vida com naturalidade e leveza. 


\section{REFERÊNCIAS}

BAPTISTA, T. J. R. Corpo e envelhecimento: um estudo de caso em Universidade Aberta à Terceira Idade. Est. Interdisc. sobre o Envelhecimento. v. 19, n. 3, p. 723-41, 2014. Disponível em: <https://seer.ufrgs.br/RevEnvelhecer/article/view/30822> Acesso em: 09 jul. 2021.

BARDIN, L. Análise de conteúdo. Portugal: Edições 70, 1977.

BARROSO, E. P. Reflexões sobre a velhice: identidades possíveis no processo de envelhecimento na contemporaneidade. História Oral, v.24, n.1, p.9-27, jan./jun., 2021. DOI: https://doi.org/10.51880/ho.v24i1.1128

BRANDÃO, C. R. (org) Repensando a pesquisa participante. São Paulo: Brasiliense, 1999.

CACHIONI, M. Universidade da Terceira Idade: história e pesquisa. Kairós gerontologia. São Paulo, v. 15, n 7, p. 1-8, 2012. Disponível em: <https://revistas.pucsp.br/index.php/kairos/article/view/15225/11354>

CIAMPA, A. C. A estória do Severino e a história da Severina - um ensaio de Psicologia Social. São Paulo: Brasiliense, 8 ed, 2005.

CIAMPA, A. C. Identidade. In: LANE, S. T. M; CODO, W. (orgs.). Psicologia social: o homem em movimento. São Paulo: Brasiliense, 8 ed, p. 58-77, 1989.

CHAUÍ, M. Apresentação: Os trabalho da memória. In: BOSI, E. Memória e sociedade: lembranças de velhos. 17 ed, São Paulo, Companhia das Letras, 2012.

DEBERT, G. G. A reinvenção da velhice. São Paulo: Fapesp, 1999.

DEBERT, G. G. O corpo e a reinvenção da velhice. In: RABINOVICH, E. P. et al. (orgs.). Envelhecimento e intergeracionalidade: olhares interdisciplinares. Curitiba: CRV, v. 2, p. 21-41, 2019.

DEBERT, G. G. Velho, terceira idade, idoso ou aposentado: sobre diversos entendimentos acerca da velhice. Revista coletiva, n. 5, 2011. Disponível em: < http://coletiva.labjor.unicamp.br/index.php/artigo/velho-terceira-idade-idoso-ouaposentado-sobre-diversos-entendimentos-acerca-da-velhice/>

FARO, A. et al. Covid-19 e saúde mental: a emergência do cuidado. Est. Psicol. Campinas, v. 37, jun. 2020. Disponível em:

$<$ https://www.scielo.br/scielo.php?script=sci_arttext\&pid=S0103166X2020000100507\&lng=pt\&nrm=iso > Acesso em: 13 jan. 2022.

FERREIRA, A. V. L. Contribuições da Oficina de Práticas Integrativas da UATI/UEFS na (re)construção identitária: narrativas das idosas participantes. TCC (Graduação em Psicologia) - Universidade Estadual de Feira de Santana, Feira de Santana, 2021. 
LIMA, A. F. Sofrimento de indeterminação e reconhecimento perverso: um estudo da construção da personagem doente mental a partir do sintagma identidademetamorfose-emancipação. 2010. Tese (Doutorado em Psicologia Social) - Programa de Estudos Pós-Graduados em Psicologia Social, Pontifícia Universidade Católica de São Paulo, São Paulo, 2010.

MARTINS, C. R. M; CAMARGO, B. V; BIASUS, F. Representações sociais do idoso e da velhice de diferentes faixas etárias. Univ. Psychol. v. 8, n. 3, p. 831-847, 2008. Disponível em: <https://www.redalyc.org/pdf/647/64712155020.pdf> Acesso em: 15 jul de 2021.

MENESES, D. L. P. et al. A dupla face da velhice: o olhar de idosos sobre o processo de envelhecimento. Enf. em foco, v. 4, n. 1, p. 15-18, 2013. Disponível em: <http://revista.cofen.gov.br/index.php/enfermagem/article/view/495/185> Acesso em: 15 jul 2021.

MOTTA, A. B. Envelhecimento e família: aportes sociológicos. In: RABINOVICH, E. P. et al. (orgs.). Envelhecimento e intergeracionalidade: olhares interdisciplinares. Curitiba: CRV, v. 2, p. 359-375, 2019.

NASCIMENTO, F. D. S. A emoção na dança e a coerção do papel de avó: considerações sobre a velhice feminina. In: LIMA, A. G. (org) Psicologia Social Crítica: Paralaxes do contemporâneo. Porto Alegre: Sulina, p. 237-268, 2012.

Organização Mundial de Saúde. Envelhecimento ativo: uma política de saúde. 1ed. Brasília: OMS; Organização Pan-Americana de saúde, 2005.

PAULA, M. F de. Os idosos do nosso tempo e a impossibilidade da sabedoria no capitalismo atual. Serv. Soc. Soc. v. 126, p. 262-280, 2016. Disponível em: <https://www.scielo.br/j/sssoc/a/KpPCVCRHWMZYRRpR3f76bVq/?format=html> Acesso em: 15 jul 2021.

SANTOS, J. D. S; BASTOS, A. C. S. O envelhecer para educadoras idosas (aposentadas): trajetórias e sentido da vida. In: RABINOVICH, E. P. et al. (orgs.). Envelhecimento e intergeracionalidade: olhares interdisciplinares. Curitiba: CRV, v. 2, p. 235-250, 2019.

SANTOS, V. B; TURA, L. F. R; ARRUDA, A. M. S. As representações sociais de "pessoa velha" construída por idosos. Saúde Soc, São Paulo, v. 22, n. 1, p. 138-147, 2013. DOI: https://doi.org/10.1590/S0104-12902013000100013

SILVA, L. R. F. Da velhice à terceira idade: o percurso histórico das identidades atreladas ao processo de envelhecimento. História, Ciências, Saúde. Rio de Janeiro, v. 15, n 1, p. 155-168, março 2008. DOI: https://doi.org/10.1590/S010459702008000100009

UEFS. Universidade Aberta à Terceira Idade, [s.d]. Disponível em < http://www.uefs.br/modules/conteudo/conteudo.php?conteudo=82 >. Acessado em: 20 de nov de 2020. 
VIEIRA, M. C.; COSTA, L. A. F. Do ócio à atividade: uma reflexão sobre envelhecimento e aposentadoria na contemporaneidade. In: RABINOVICH, E. P. et al. (orgs.). Envelhecimento e intergeracionalidade: olhares interdisciplinares. Curitiba: CRV, v. 2, p. 181-195, 2019.

Recebido em: 08/01/2022

Aprovado em: 10/02/2022

Publicado em: 14/02/2022 